appeared : and at the end of 4 weeks his eyes had returned to their normal colour.

On September 13, 1929, I saw the patient for the first time and he had then very extensive, symmetrical, bilateral subconjunctival haemorrhages, but no evidence whatsoever of vascular changes in his fundi. His vision right and left was 6/6.

The one outstanding feature of this case, as compared to similar cases reported, is the surprisingly short duration of the compression of the chest, which resulted in such extensive latent signs. On this question of duration, Foster Moore in his book on Medical Ophthalmology makes the following statement:-“"In some instances of traumatic asphyxia from severe compression of the chest of long duration, ocular complications may arise : ....'

\title{
SOME EARLY ROYAL OCULISTS
}

\author{
BY
}

\author{
R. R. JAMES \\ LONDON
}

EARLY last year the plate which is reproduced to illustrate this article was sent to me by $\mathrm{Mr}$. Holmes Spicer, in the hope that I might be able to furnish our readers with some account of Thomas Clarck. It had belonged to Sir Anderson Critchett and was bound in brown paper on which was stamped "Dedication Plates and Records, 1688." I am not learned in prints, but this would appear to be a rather rough wood block, and it will be seen that the name of the engraver is omitted. The first thing to settle was where the plate came from. Mr. H. E. Powell, Librarian of the Royal Society of Medicine, suggested that it was from a History of the. Bible, by Le Sieur de Royaumont, translated by J. Coughan and J. Raynor, printed for Robert Blome, 2 vols., roy. folio, 1690-98, with 238 plates. An extended research by $\mathrm{Mr}$. Harvey Bloom at the British Museum, Sion College, and the British and Foreign Bible Society, has failed to locate it. Mr. Bloom writes, "It ought to belong to Le Sieur' Royaumont's Histoire but neither edition contains the Apocrypha. I am inclined to think that plates were prepared for such a purpose but the volume never printed. Blome published no Bible."

I have drawn blank in all the usual books of reference, and in spite of the large amount of negative evidence, have decided to print what I know about three early Royal oculists, namely Thomas Clarck, 'Thomas Elles or Ellis and Paddington Macqueen. 


\section{Thomas Clarck}

I find a Thomas Clarke, Anglus, in Peacock's Index of English speaking Students who have graduated at Leyden University, under date 31 Martii, 1664. In June, 1656, Thomas Clarke, A.B. (Oxon), was admitted Extra-Licentiate of the College of Physicians (Munk.) According to Foster's Alumni Oxonienses, 1st Series, Vol. I, this Thomas Clarke was " 2nd son of Edward Clarke, of Ardington, Berks, militis, Wadham College, matriculated 2 Nov. 1627, aet. 15. B.A., 1629, of Gray's Inn, 1643 ; called Bachelor of Physic in the Visitation of 1664.'

Search in Venn's Alumni Cantabrigienses and Musgrave's Obituary has yielded nothing ; search in histories of St. Andrew's, Holborn, has also proved negative and an extensive search at the Public Record Office has failed to find the warrant of appointment. Mr. Harvey Bloom, who kindly undertook the research, writes : "I have searched the records of the Privy Seal and Signet Office, both the Docquet Books and indices. I hardly know under which heading an oculist at that date would be placed, whether as surgeon or goldsmith. I fancy these men were not members of the Household, but employed as occasion served. Had they been formally appointed I must have found the warrant under the Privy Seal or Signet." We have no evidence, save for the inscription on the plate, that Clarck was sworn "Phisitian Oculist in ordinary to King Charles ye 2nd and to King James ye 2nd, in whose presence apparently he couched a cataract in a lady 15 years blind and restored her sight in an instant." He (possibly in a fit of remorse) contributed the plate of 'Tobit's restoration of sight to some work to be published by Blome. Would it be fair to suggest that when the question of paying for the plate arose, Clarck was a defaulter, and so the plate was never published?

It will be seen that a coat of arms appears in the middle of the inscription on the plate. This can be blazoned as follows :Argent, on a bend gules, between three Ogresses as many swans proper. The crest is a lark, with wings expanded proper, holding in the beak an ear of corn. According to Burke's Landed Gentry, this coat is borne by the family of Clark of Bridwell, in Halberton, Co. Devon. Edmonson, Display of Heraldry, gives the same coat for the family of Clarke of Northampton, and the same coat, without the crest, is given for Clarke of London. Burke gives the Northampton Clarke a similar coat, but he calls the Ogresses, Torteaux. The difference is that Torteaux means red pellets and Ogresses black pellets.

The visitations of London and Northampton do not help in the matter. It is highly probable that Thomas Clarck, M.D., had no right to bear arms at all, and that he appropriated a Clark coat from some other family. 


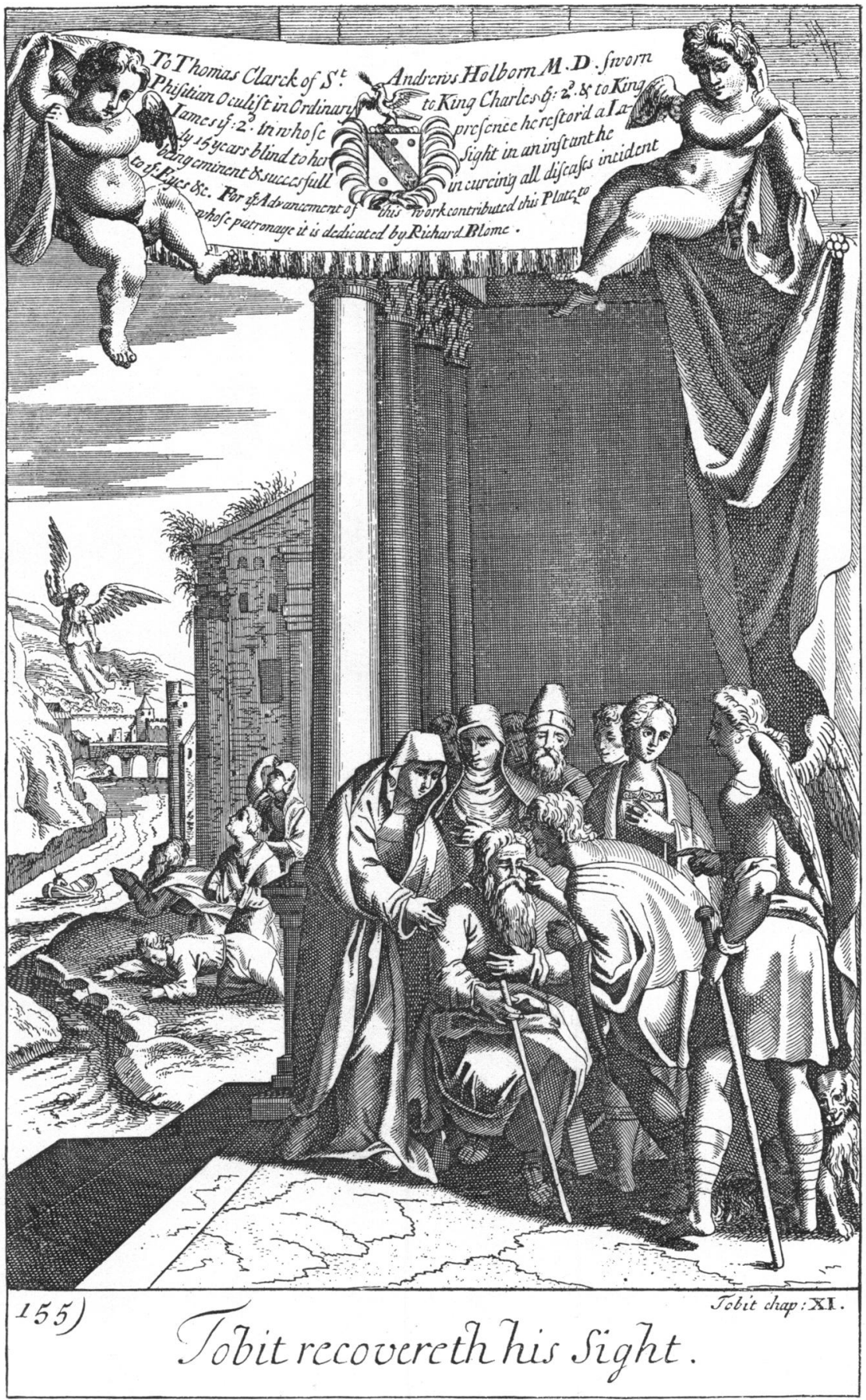

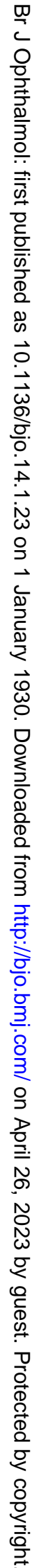


Thomas Ellis

From the obituary in the Gentleman's Magazine for the year 1735 we get the following note. "Feb. 3.; 'Thos. Elles, aet. 92, oculist to James II and groom of the Chamber, deceased." An identical notice appeared in the Historical Register (Chronological Diary), with the exception of the name being spelt Ellis. The Political State of England for February, 1735, says that he died at Windsor on February $2 \pi$.

\section{Paddington MacquenN}

From the obituary in the Gentleman's Magazine for the year 1736 we get: "March 16.; Paddington Macqueen, at Betley, Staffs., late oculist to William III, worth $£ 16,000$, deceased." The notice in the Historical Register is identical; while the Political State of England for March, 1736, gives, "March 9, Died at his Seat in Staffordshire, Paddington Macqueen, Esq., formerly oculist and Groom of the Chamber to the late King." As regards their Royal appointments the same remarks made about Thomas Clarck apply in the case of both Ellis and Macqueen. Mr. Bloom searched for five.years in each case in the wills of the P.C.C., those of the Court of the Dean and Chapter of Westminster and the Commissary of London, without result. He says it is most unusual to find no will or admon. in the case of so rich a man as Macqueen. He consulted London newspapers as well as the Indices of the Society of Genealogists and found nothing. The name Macqueen does not occur in the volumes of the IVilliam Salt Society, the Archaeological Society for Staffordshire, nor in Stebbing Shaw's History of that county. Macqueen was not buried at Betley; some years ago I wrote to the then owner of Betley Hall, who happened to be a girl friend of my mother, and asked her to get the Rector to search the parish registers. This was done and nothing was found. It was suggested that as the name was a Scottish one, Macqueen might have been buried in Scotland. It is possible that Macqueen's will might have been proved at Lichfield, but $\mathrm{Mr}$. Bloom thinks this unlikely as he was so wealthy a man. He tells me that the Lichfield wills are now kept at Birmingham. He has also ascertained that Macqueen's will was not proved in any Probate Court in Scotland; nor is there any record of it at Birmingham. Thomas Ellis, though stated to have died at Windsor, was not buried there. There is no record of the appointment, of either Ellis or Macqueen as Groom of the Chamber, to be found in the warrant books of the Lord Chamberlain's Office for the years 1660-1665 : 1676-1680: 1685-1688. I think it will be conceded that no stone has been left unturned in the effort to provide facts about these three Royal 
oculists. The results of this search are disappointing, but as $\mathrm{Mr}$. Harvey Bloom says :- " "There is no period so difficult to trace people in as the late 17th and early 18th centuries."

I have thought it best to record all this negative evidence here in case any ophthalmic surgeon in the future should be tempted to try his hand at these three men, for it will save him much time and trouble knowing the search which has already been made.

\section{ANNOTATIONS}

\section{Blindness in India}

The Committee of the All-India Blind Relief Association, having its headquarters in Bombay, has sent us a copy 'of a letter which has been addressed to H. E. The Viceroy of India, together with pamphlets and other literature dealing with blindness in India.

Statistics as to the number of blind in India vary greatly; census returns show 1.5 per thousand for totally blind persons, but the Association has reasons for considering this figure far too low. Thus in 1918-19 in the Nasik district, for which census figures show an incidence of 1.74 per mille, an actual count in four talakas in villages with a population of 212,000 showed an incidence of at least 4.38 per mille. A few years ago a Deputy Commissioner in the United Provinces had a similar count made and discovered an incidence of no less than 9 per mille. In Palinpur an incidence of 7 per mille has been noted. The Association has reasons for believing that instead of the half million totally blind persons in India shown in the census returns, the true number is about treble. This refers to those totally blind in both eyes and takes no account of uniocular blindness. The Association, in an analysis of cases attending their camps and dispensaries, has found that for every totally blind person there are three with more or less damaged vision.

The fact that much of this blindness is preventable and that a great deal is remediable is commented on. Industrial accidents are, we believe, very rare in India and the main causes of blindness are cataract, glaucoma, untreated ophthalmia and neglected corneal ulcers. The Association points to the splendid work accomplished in Egypt by the ophthalmic services established, in the first place, through the generosity of Sir Ernest Cassell.

$\mathrm{Mr}$. Charles Henderson, I.C.S., would appear to have been the first to attempt to ameliorate this lamentable state of affairs in India, and now the All-India Blind Relief Association has been formed, with Mr. Henderson as President, in order to attempt 